\title{
PHILOSOPHIAE PORTUS E ARX PHILOSOPHIAE: APROPRIAÇÃO E SUPERAÇÃO AGOSTINIANA DA TRADIÇÃO FILOSÓFICA GREGO-ROMANA EM RELAÇÁO À FELICIDADE
}

\author{
Marcos Roberto Nunes Costa ${ }^{1}$
}

\begin{abstract}
RESUMO: Mantendo-se na linha de São Justino, o qual, apesar de valorizar a Filosofia Grego-Romana, defende ser o Cristianismo a "verdadeira filosofia", Agostinho fundamenta ou alicerça seu conceito de felicidade na tradição filosófica que o antecedeu, a qual é concebida por ele como um philosophiae portus (porto da filosofia). Entretanto, como pensador cristão, buscando superar o eudaimonismo grego-romano, ao distinguir sabedoria e Verdade, sendo esta última identificada com Deus, faz da Fé Cristã o arx philosophiae (ápice da filosofia), a que chama de "nossa Filosofia Cristâ", lugar da "verdadeira felicidade", que, para ele, é a principal finalidade de todo filosofar.
\end{abstract}

PALAVRAS-CHAVE: Agostinho. Filosofia Grego-Romana. Filosofia Cristá. Felicidade.

Sabemos que uma das preocupaçôes centrais da Filosofia grego-romana era a busca da felicidade, a qual ficou conhecida pelo nome de eudaimonia, e esta, de uma forma ou de outra, poderia ser alcançada, ainda nesta vida, unicamente pelo esforço humano, mediante um exercício dialético da razáo que se autocompreende e se manifesta como verdade-felicidade, conforme salienta Bento Silva Santos, ao introduzir um dos volumes da traduçáo recente de uma das obras agostinianas, pela Editora Paulus:

Por meio dela, a razão mesma manifesta e descobre sua própria natureza, o que deseja e o que pode; e oferece à alma racional os meios para que se reconheça a si mesma: sua origem, seu valor ontológico e os princípios superiores a ela. A dialética corresponde, pois, à atividade da pura razáo e, por seu método puramente racional que tão só comporta operaçóes

Professor/coordenador da Graduação em Filosofia da UFPE. Professor do Programa de PósGraduação (Mestrado e Doutorado) em Filosofia da UFPE/UFPB/UFRN. Atual vice-presidente da Associação Brasileira de Estudos Medievais - ABREM. E-mail: marcosnunescosta@hotmail.com 
estritamente lógicas, assegura o caráter científico das outras ciências ou disciplinas. (SANTOS, 2008, p. 18).

Agostinho absorveu e apropriou-se da Filosofia grego-romana, a qual não abandonará pelo resto da vida, notadamente no que se refere ao eudaimonismo, o qual aparece nitidamente expresso em duas passagens do Sobre a Cidade de Deus, uma das obras da maturidade, quanto escreve:

Não há razão para o homem filosofar senão para que seja feliz; e o que faz com que este seja feliz é o fim bom; não há, por conseguinte, nenhuma causa para o filosofar, salvo a meta do bem; por essa razão, aquela que não segue o fim bom não pode ser dita seita filosófica. (De civ. Dei, XIX, 1,3).

Não só nessa passagem, mas em muitos outros momentos, Agostinho acentua seu eudamonismo, como, por exemplo:

É pensamento unânime de todos quantos podem fazer uso da razão que todos os mortais querem ser felizes. Mas quem é feliz, como tornar-se feliz, eis o problema que a fraqueza humana propóe e provoca numerosas e intermináveis discussóes [...] (De civ. Dei, X, 1).

Esse é o problema central - a busca da "Verdadeira Felicidade" - que perpassa toda a produção literária de Agostinho, desde os primeiros Diálogos Filosóficos de Cassicíaco, passando pelas dezenas de Tratados e centenas de Cartas e Sermóes, o que levaria o agostinólogo brasileiro Manfredo Ramos a sustentar que "[...] essa constatação ele a póe na base e no início de todas as suas argumentaçôes, em resposta às mais variadas interrogaçóes ou situaçóes [...]" (RAMOS, 1984, p. 48)2.

Em uma de suas Epistolas (130), ao aconselhar à rica viúva Proba sobre o que pedir em oração, Agostinho enfatiza que a busca da felicidade é algo imanente ao homem, fazendo, assim, parte da natureza humana: todos os homens, bons e maus, desejam-na:

Todos os homens querem possuir vida feliz, pois mesmo os que vivem mal não viveriam desse modo, se não acreditassem que, desse modo, são, ou

\footnotetext{
${ }^{2}$ Em sua obra anterior (RAMOS, 1966, p. 10), o autor ressalta: "De fato esta - a felicidade - constitui, para Agostinho, o problema central da vida do homem. E suas principais cartas de espiritualidade têm este fundo comum de base: onde encontrar a verdadeira vida feliz, a autêntica bem-aventurança”.
} 
que podem vir a ser felizes. Que outra coisa te convém pedir se não o que bons e maus procuram adquirir, ainda que somente os bons consigam? $(\text { Ep., 130, 4,9) })^{3}$.

Entretanto, se Agostinho adota o eudaimonismo da tradição gregoromana como bem a ser almejado por todo homem vindo a este mundo, ${ }^{4}$ discorda dela quanto ao lugar onde o encontrar e ao método para alcançá-lo, fazendo da razão ou Filosofia não mais um fim em si mesmo, mas um meio ou um porto (philosophiae portus), transformando a felicidade em "verdadeira felicidade" (beatitudo), a ser alcançada unicamente em Deus, e a Fé revelada em "verdadeira filosofia" (arx philosophiae), estabelecendo uma distinção entre sabedoria, alcançada pela Filosofia, e Verdade - Deus, revelada no Cristianismo, e nisso reside a originalidade de nosso Filósofo cristão em relação à tradição filosófica grego-romana.

Já no Sobre a Vida Feliz, um dos Diálogos Filosóficos de Cassiciaco, por exemplo, tentando responder às questóes "Onde está a felicidade?" - "Como e onde o homem pode ser feliz?" - depois de buscar e náo encontrar, entre as doutrinas filosóficas dos Antigos e, entre os bens materiais, um que possa trazer a "Verdadeira Felicidade", uma vez que são todos mutáveis, Agostinho escreve:

Por conseguinte, estamos convencidos de que, se alguém quiser ser feliz, deverá procurar um bem permanente, que não lhe possa ser retirado em algum revés da sorte. (De beat. vita, I, 12) ${ }^{5}$.

No final do referido Diálogo, Agostinho chega à conclusão de que a "Verdadeira Felicidade" está em Deus, ou só é verdadeiramente feliz quem possui a Deus ${ }^{6}$. Nesse sentido, a Filosofia agostiniana diferencia-se em muito

\footnotetext{
${ }^{3}$ Igualmente, na Epístola 104, ao pagão Nectário, Governador da Calama, Agostinho repete: “Todos queremos ser felizes, isto é, tendemos para felicidade [...]" (Ep., 104, 3).

${ }^{4}$ A esse respeito, diz Beraldi (2010, p. 45): "Em relação às aproximações, num âmbito mais geral, podemos dizer que em comum com os três pensadores acima referidos [Cícero, Sêneca e Plotino] Agostinho tinha a certeza que todos os homens tendem para a felicidade e que a vida virtuosa lhe é constitutiva”.

${ }^{5}$ Por isso, Arendt (1997, p. 19) afirma que, em Agostinho, “[...] a beatitude (beatitudo) consiste na posse (habere, tenere) do bem e mais ainda na segurança da não-perda”.

${ }^{6}$ Mais tarde, no Sobre a Cidade de Deus, Agostinho confirmaria a ideia de que o único e verdadeiro bem imutável que torna o homem verdadeiramente feliz é Deus: "Dizemos existir apenas um bem imutável,
} 
da Filosofia Antiga, ao transferir o fundamento último de seu eudaimonismo para o sobrenatural, conforme palavras de Frederick Copleston:

A ética de Santo Agostinho tem em comum com o que poderíamos chamar típica ética grega seu caráter eudaimonista, quer dizer, o que se propóe é um fim comum para conduta humana, a saber, a felicidade; porém essa felicidade tem de encontrar-se unicamente em Deus. (COPLESTON, 1983, p. 87).

Assim sendo, em Agostinho, a busca da felicidade do homem convertese na procura ou busca de Deus, o único que pode dar-lhe estabilidade. As inquietudes e as dúvidas, as quais fundamentam a natureza própria do homem, não deixam de ser outra coisa, senão a ânsia por conhecer a si mesmo e a Deus; por isso, ao estabelecer uma relação entre Filosofia e Felicidade, destaca:

Que o filósofo tenha amor a Deus, pois se a felicidade é o fim da filosofia, gozar de Deus é ser feliz. (De civ. Dei, VIII, 9).

Igualmente, já nos Solilóquios, outro Diálogo Filosófico de Cassiciaco, depois de uma longa oração a Deus, Agostinho inicia o diálogo consigo mesmo [ou com a razão] desta forma:

A - Eis que já orei a Deus.

$\mathrm{R}$ - Pois bem, o que queres saber agora?

A - Tudo o que acabo de pedir em minha oraçáo.

$\mathrm{R}$ - Resume isso brevemente.

A - Desejo conhecer a Deus e à alma.

$\mathrm{R}$ - E nada mais?

A - Nada mais absolutamente! (Sol., II, 2,7) .

Para Agostinho, o filósofo procura a verdade, não simplesmente para ser sábio, mas para ser feliz, e coloca tal felicidade onde realmente ela se encontra, a saber, "[...] na posse de um bem imutável [...] a verdade - Deus" (Ep., 118,

Deus, uno, verdadeiro e feliz" (De civ. Dei, XII, 1). Além das duas obras aqui referidas, são inúmeras as obras em que Agostinho reforça essa ideia.

${ }^{7}$ Para Gilson (1949, p. 11), “[...] é fato capital para compreensão do agostianismo que a Sabedoria, objeto da filosofia, tenha se confundido sempre para Agostinho com a beatitude ou felicidade. O que ele procura é um bem tal, que sua posse satisfaça todo desejo e, portanto, em consequência, que traga a paz". Para o mesmo comentador, aqui reside a chave do eudaimonismo antropológico de Santo Agostinho, ao transformar o problema da filosofia e do homem em um só problema: a busca da felicidade, da verdade, de Deus mesmo, que é a "Verdadeira Felicidade". 
1,6). Desse modo, quem procura a felicidade busca a Deus, e só ao encontrar a Deus encontrará a felicidade.

Além de divergir dos antigos Filósofos quanto ao lugar onde a felicidade se encontra, Agostinho discorda também a respeito do método ou caminho a ser alcançado, quando, embora não negando totalmente o papel da razão ou Filosofia, coloca como condição sine qua non a intervenção da Graça divina, atribuindo não ao homem, mas ao próprio Deus, que se revela enquanto Verdade-Felicidade, o mérito de tal ação. Não que Agostinho negue totalmente o papel da razáo ou Filosofia, nesse processo, mas apenas que esta, por conta própria, não é suficiente para alcançá-la, senão mediante o auxílio da Graça divina, conforme declara no Sobre a Ordem, outro Diálogo Filosófico de Cassiciaco, rebatendo o sensitismo estoico:

[...] deve-se, portanto, dizer divina aquela autoridade que [...] dirigindo o próprio homem, mostra-lhe até que ponto se rebaixou por ele e lhe ordena que não fique preso aos sentidos [...], mas se eleve ao entendimento [...]. Parece-me, pois, uma grande verdade que somente homens divinos, ou não sem auxílio divino, vivem desse modo. (De ord., II, IX, 27).

Igualmente no Contra Acadêmicos, mais um Diálogo Filosófico de Cassiciaco, referindo-se aos neoplatônicos, acentua a necessidade da Graça divina no caminho da Verdade:

[...] a sutileza da razão [humana] jamais teria levado as almas cegas pelas multiformes trevas do erro e obliteradas sob a enorme massa das impurezas corporais, se o sumo Deus, movido de misericórdia pelo seu povo, não tivesse inclinado e abaixado até o corpo humano a autoridade do Intelecto divino. (Contra acad., III, XIX, 42).

Aliás, o reconhecimento da necessidade da Graça divina como único caminho para se alcançar a Verdade era o que faltava ao jovem Agostinho para se converter ao Cristianismo, desde que despertara para tal, depois da leitura do Hortênsio, de Cícero, aos 19 anos de idade. Nas Confissóes, ele sublinha que, momentos antes de sua conversão, aconselhado pelo Bispo Ambrósio, procurou Simpliciano e contou-lhe acerca das importantes descobertas que fizera, ao ler os escritos neoplatônicos, porém, revelou-lhe que continuava inquieto e angustiado. Este reforçou os méritos dos neoplatônicos, contudo, chamou-lhe a atenção para um grave erro: o orgulho (soberba) ou presunção 
do saber, por parte destes. E apontou o orgulho intelectual como um dos males que sufocava e ofuscava o coração de Agostinho, naquele momento, impedindo-o de ver a verdade. E, como solução para tal problema, Simpliciano exalta a necessidade da humildade cristá e da graça redentora de Cristo; de reconhecer Cristo como único salvador, para se chegar à verdade. Esse aspecto faltava nos neoplatônicos e a Agostinho ${ }^{8}$, pois, naquele momento, ele náo conseguia entender o "Mediador de Deus e dos homens, Jesus Cristo homem, Deus soberano". Ele náo entende como Jesus Cristo pôde humilhar-se a ponto de encarnar-se, habitar entre os homens e morrer sobre a cruz, como ele mesmo diz: "Eu não era humilde, e eu não tinha a humildade de Jesus por meu Deus, nem sabia de que coisa poderia ser mestra a sua fraqueza" (Conf. VII, 18, 24). Simpliciano o faz ver que

[...] os filósofos podem, a rigor, com as forças de seu pensamento - que a Verdade, por outra parte, dirige sempre secretamente - descobrir e mostrar aonde ir, mas não por onde ir; são capazes de elevar-se à contemplaçáo da pátria feliz, mas não de habitá-la; vêem o fim, mas desconhecem os meios. É que se trata de algo muito distinto do especular: trata-se de vencer as paixóes, de reformar o coração, de fortalecer a vontade, e isso não é possível senáo pela graça de Cristo. (JOLIVET, 1932, p. 103).

Por isso, escreve Agostinho, nas Confissóes:

Uma coisa é ver de um píncaro arborizado a pátria da paz e não encontrar o caminho para ela, gastando esforços vãos por vias inacessíveis [...]; e outra coisa é alcançar o caminho que para lá conduz, defendido pelos cuidados do general celeste... (Conf. VII, 21, 27).

No final da conversa, Simpliciano, percebendo ser necessário que Agostinho se munisse daquela caridade em que se baseia o fundamento da humildade, quer dizer, de Jesus Cristo, para chegar à Verdade, recomenda-lhe ler as Sagradas Escrituras, especialmente São Paulo, onde poderá encontrar o caminho que lhe faltava. E foi o que fez Agostinho, conforme relata:

\footnotetext{
${ }^{8}$ A esse respeito, Sciacca (1956, p. 5) argumenta: "Agostinho não encontra então nos platônicos a ideia de que o Verbo se fez carne; ele náo encontra ali o que lhe interessa verdadeiramente e sobre o que ele precisa de luzes.[...] ele não encontra neles a Encarnaçấo do Verbo. [...] ele não descobre os esclarecimentos que ele buscava. Com efeito, é precisamente a encarnação que lhe parece obscura, ele não consegue compreender como o Verbo se fez carne".
} 
Por conseguinte, lancei-me avidamente sobre o venerável estilo (da Sagrada Escritura) ditada pelo vosso Espírito, preferindo, entre outros autores, o apóstolo Sáo Paulo [...]. Compreendi e notei que tudo o que de verdadeiro tinha lido ali (nos livros platônicos) se dizia aqui realçado com a tua graça... (Conf. VII, 21, 27).

Com uma grande diferença: os livros platônicos, ao identificarem o Verbo de Deus - o Lógos de São João - com o Nô̂s - a razão, esqueciam-se de dizer que "[...] o Verbo se fez homem e habitou entre nós" (Jo 1,13). Nesse sentido, salienta:

Li nesse lugar (nos livros platônicos) - não certamente com estas palavras, mas sim substancialmente o mesmo, apoiado em muitas e diversas razóes - que "no princípio era o Verbo, e o Verbo estava em Deus [...]. Também li ali que o Verbo, Deus, náo nasceu da carne, nem do sangue, nem da vontade da carne, mas de Deus. Porém, que "o Verbo se fez homem e habitou entre nós” (Jo 1,13), isso não li eu ali. Igualmente li naqueles livros (dos platônicos), dito de diversas e múltiplas maneiras, que o Filho tem a mesma condição do Pai e que náo foi injúria julgar-se igual ao Pai, por ter a mesma natureza que ele". Mas que "se anulou a si mesmo, tomando a forma de servo, feito semelhante aos homens e reconhecido como tal por seu modo de ser; e que se humilhou, fazendo-se obediente até à morte, e morte de cruz" [...], não o dizem aqueles livros. (Conf. VII, 9, 14).

Por isso, depois de muitas outras comparaçóes mostrando o valor da humildade cristá como único caminho para se alcançar a verdade, o Cristo como mediador e redentor, conclui Agostinho:

Todas essas coisas penetraram-me até às entranhas, por modos admiráveis, ao ler (São Paulo) "o mínimo de teus Apóstolos, e considerava suas obras, e me sentia espantado, fora de mim”. (Conf. VII, 21, 27).

A leitura de São Paulo, orientada pelos comentários de Simpliciano, fizera Agostinho perceber que, apesar de serem os que mais se aproximam das Verdades da fé’, os quais chegaram aos últimos limites do que a razão humana

\footnotetext{
${ }^{9}$ No Sobre a Cidade de Deus, assinala: "Se Platão disse ser sábio quem imita, conhece e ama a Deus, de cuja participação depende ser feliz, que necessidade há de discutir as outras Doutrinas? Nenhuma se aproxima da nossa mais do que a deste" (De civ. Dei VIII, 5). E mais adiante: "Compreenderam os platônicos, a quem vemos, não imerecidamente antepostos aos demais em glória e fama, que nenhum corpo é Deus. Por isso, transcenderam todos os corpos em busca de Deus [...]. Assim, o que é possível
} 
pode dizer da Verdade, aos platônicos faltava um último degrau para alcançála; que os neoplatônicos, ao identificarem o Verbo com o Noûs - ou razão natural, esquecerem que o Verbo não é somente Deus, mas Deus encarnado; que o "Verbo se fez carne e habitou entre nós".

Entendemos que, mais tarde, depois de convertido, Agostinho diria que os "platônicos" chegaram até as portas do céu, mas não entraram, atolando-se no seu próprio orgulho racional, ao pensarem que o mais alto grau da felicidade - a eudaimonia - se encerrava no pleno exercício da razão natural o qual eles imaginavam ter alcançado - ou como ressalta Courcelles:

Os platônicos acreditavam na autonomia espiritual dos homens. Pois, segundo seu discípulo Porfírio, estas teriam sido as últimas palavras de Plotino: "Esforço-me por fazer remontar o que há de divino em nós, ao que há de divino no universo". Deste modo, o eu de origem divina não esperava uma libertação, só devia tomar consciência de sua origem divina. (COURCELLES, 1998, p. 111) ${ }^{10}$.

conhecer de Deus, naturalmente, os platônicos conheceram [...]” (Ibid., VIII, 6). Agostinho vê tanta semelhança entre o platonismo e as verdades reveladas que chega a levantar a hipótese de que Platão tenha conhecido a Bíblia: "Ademais, nada existe de mais claro nas Sagradas Letras que o que Platão diz, a saber, que o que ama Deus é o filósofo. E máxime aquilo que a mim quase me induz a dar assentimento a que Platão não fosse alheio a esses Livros" (Ibid., VIII, 9).

${ }^{10}$ Igualmente Campodonico (1989, p. 113), demonstrando que Agostinho, antes da conversão, havia partilhado do mesmo erro dos neoplatônicos, escreve: "Em um primeiro momento, fascinado pela mística neoplatônica, Agostinho pensa poder compenetrar-se com o Deus trinitário por meio de uma ascese baseada unicamente nas forças humanas. Em seguida, ainda em idade juvenil, a intencionalidade juntamente intelectiva e afetiva de Agostinho sempre mais se volta para Cristo. Somente a encarnaçáo de Cristo torna possível a efetiva aproximação com aquela 'pátria ideal', isto é, aquele estado de beatitude e de perfeição que os pagãos tinham previsto, mas que não estavam em grau de conseguir”. Já Muńoz veja (1981, p. 23), ao apontar a grande diferença entre o pensamento de Plotino e o de Agostinho, declara: "O influxo do espiritualismo neoplatônico no pensamento agostiniano foi sem dúvida extraordinário. Entretanto, o caminho seguido por Agostinho e pelos neoplatônicos, e sobretudo a orientaçáo de suas almas, diferem imensamente. Como Plotino, Agostinho pode entrar dentro de si mesmo, ascender pelos diversos graus da natureza corpórea e espiritual como por degraus, elevar-se até o mais alto do espírito, transcender tudo e tocar finalmente em um mundo puramente espiritual da Verdade. Mas esta Verdade não é uma Unidade que permanece imóvel e sem vida, como um teorema de matemática, senão uma Pessoa cujo maior amor infinito regenera e redime suas criaturas. A ascensão agostiniana é efetivamente busca intelectual, evasão espiritual e contato extratemporal como a de Plotino; mas é ademais atraçấo sobrenatural do Verbo, Luz inefável que previne, convida, solicita, busca, ilumina e governa os passos vacilantes dos homens". 


\title{
Assim, Agostinho, denunciando o seu próprio orgulho racional antes da conversão e, ao mesmo tempo, o dos neoplatônicos ${ }^{11}$, afirma:
}

Tagarelava a boca cheia como um sabichão, mas, se não buscasse em Cristo Nosso Salvador o caminho para Vós, não seria perito mas perituro ${ }^{12}$. Já então, cheio do meu castigo, começava a querer parecer um sábio; não chorava e, por acréscimo, inchava-me com a ciência. (Conf. VII, 20, 26) ${ }^{13}$.

\begin{abstract}
As palavras de São Paulo mostraram-lhe que a "verdadeira sabedoria", sinônimo de "verdadeira felicidade", não se encontra neste mundo, mas tão somente em Deus, que é o arx philosophiae, e que Este não se atinge pela razão, mas, para alcançá-Lo, é preciso transcender a razão; que só mediante
\end{abstract}

${ }^{11}$ É por isso que, apesar de reconhecer a grande contribuição dos neoplatônicos, especialmente Plotino, cuja doutrina do Noûs é análoga ao Verbo de São João (cf. Conf. VII, 9,13 e De civ. Dei $\mathrm{X}, 29,2)$, e Porfírio, no qual se encontra uma teoria da Trindade, compreendendo o Pai, o Filho (chamado intelecto) e ainda uma terceira hipóstase, como termo intermediário (cf. De civ. Dei X, 23), Agostinho lamenta que tais filósofos tenham caído em um lamentável fracasso, porque sua soberba os envergonhava de confessar a encarnação do Verbo. Agostinho dedicaria três livros inteiros do Sobre a Cidade de Deus (Livros VIII a X - intitulados, respectivamente, "Teologia Natural e Filosófica", "Cristo Mediador" e "O Culto ao Verdadeiro Deus"), para elogiar a filosofia platônica, mas, também, para mostrar os seus limites, ou seja, que pela razão filosófica não se chega à verdade, mas, tão somente, a uma falsa verdade, ou soberba. Igualmente, no Sobre a Doutrina Cristä, assevera: "Os que são chamados filósofos, especialmente os platônicos, quando puderem, por vezes, enunciaram teses verdadeiras e compatíveis com a nossa fé, por isso é preciso não somente não serem eles temidos nem evitados, mas antes que reivindiquemos essas verdades para nosso uso, como alguém que retoma seus bens a possuidores injustos. [...] Ora, dá-se o mesmo em relação a todas as doutrinas pagãs. Elas possuem, por certo, ficçóes mentirosas e supersticiosas, [...] que cada um de nós, sob a conduta de Cristo, ao deixar a sociedade dos pagáos, deve rejeitar e evitar com horror. Mas eles possuem, igualmente, artes liberais, bastante apropriadas ao uso da verdade [...]” (De doc. christ.,II, 41, 60).

12 "Perito" - Verdadeiro saber que leva à salvação. "Perituro"- Falso saber que leva à morte, ou à condenação. Igualmente, no Sobre a Cidade de Deus, inspirado nas palavras do Apóstolo: "A ciência infla e a caridade edifica", Agostinho denuncia: "A ciência não é útil senão quando acompanhada pela caridade e, sem a caridade, a ciência infla o coração e o enche do vento da vanglória. Assim, os demônios têm a ciência sem a caridade" (De civ. Dei, IX, 20).

${ }^{13}$ Gilson (1932, p. 31), comentando essa passagem, enfatiza: "Pois, se existe um ponto evidente entre todos aqueles que o texto das Confissóes toca, é justamente que aos olhos de Agostinho a base radical do neoplatonismo tinha sido a ignorância”. 
a humildade cristã $^{14}$, pela gratuidade de pensamento, por contemplação, o homem pode alcançá-Lo ${ }^{15}$.

E essa Verdade-Felicidade encontra-se no próprio homem, na sua interioridade, não num sentido panteístico, contudo, como imanênciatranscendência, quando Deus se revela ao homem enquanto Verdade. Por isso, superando a máxima socrática do "conhece-te a ti mesmo", ele afirma, no Sobre a Verdadeira Religião:

Entre em ti próprio, no interior do homem habita a verdade; E se encontrares mutável tua natureza, transcende a ti mesmo; Mas recordate: transcendendo-te, transcendes tua alma racional. Encaminha-te, pois, para onde se esconde a própria luz da razão. Pois, aonde chega todo bom pensador senão à verdade? (De vera rel. 39,72) ${ }^{16}$.

\footnotetext{
${ }^{14}$ Sciacca (1955, p. 395) resume bem a evolução do pensamento de Agostinho, depois da conversa com Simpliciano e da leitura das Epístolas de São Paulo, quando, ao mostrar a diferença entre o eudemonismo antigo, especialmente dos estoicos e dos neoplatônicos, e o ceticismo dos acadêmicos e, finalmente, de todos eles com o novo eudeimonismo agostiniano, ressalta: "É errônea a posiçẫo acadêmica, ao tentar demonstrar que a mente humana seja incapaz da verdade [...]. Mas é errôneo, também, afirmar com os estóicos, e também com os neoplatônicos, que a realização do fim último do homem seja obra exclusivamente do homem mesmo, porque ele por si e somente com seus próprios meios não pode dar-se à felicidade. Portanto, estão equivocados os acadêmicos, quando condenam a razão à dúvida invencível e perpétua [...]. Mas têm, em certo sentido, razão ao considerar a busca como inesgotável e sem fim, ainda que seja por motivos distintos de Agostinho. Assim sendo, têm razáo os estóicos e os neoplatônicos ao afirmar que o homem é capaz da verdade, mas se equivocam, quando sustentam que a mesma sabedoria, ou a felicidade, é uma conquista sua, fruto humano da humana virtude. E todos eles, inclusive Cícero, têm razão ao assinalar como fim da filosofia a busca da felicidade, mas, conscientes do fim, por ignorância não sabem indicar o meio ou a via para consegui-la, antes, assinalam como meio a filosofia mesma que, revelando-se insuficiente, engendra desconfiança e ceticismo, como é o caso dos acadêmicos. A filosofia, portanto, uma vez que Deus é o fim e felicidade do homem, não dispóe de todos os meios para realizá-la, e nesse ponto deve a filosofia se encontrar com a religiáo, com a Verdade revelada, que se faz patente a convivência do momento racional e do religioso, a convergência das duas ordens da verdade: a filosofia, atividade humana e natural, encontra seu complemento no Verbo ou verdade de fé, sem negar ou perder sua positividade". Essa é a posição a que chegará Agostinho, a partir da descoberta das verdades da fé.

${ }^{15}$ Comentando tal passagem, sublinha Brachtendorf (2008, p. 124): "Para Agostinho, o conhecimento de Deus pressupóe, portanto, a dissolução da fixação no mundo exterior como também o retorno ao eu pela auto-reflexão. Às teses fundamentais de Agostinho pertence a convicçáo de que o caminho do homem a Deus conduz do exterior pra o interior e do interior para cima".

${ }^{16}$ Comentando tal passagem, sublinha Brachtendorf (2008, p. 124): "Para Agostinho, o conhecimento de Deus pressupóe, portanto, a dissolução da fixação no mundo exterior como também o retorno ao eu pela auto-reflexão. Às teses fundamentais de Agostinho pertence a convicção de que o caminho do homem a Deus conduz do exterior pra o interior e do interior para cima”.
} 
COSTA, Marcos Roberto Nunes. Philosophiae portus and arx philosophiae: The Augustinian appropriation and overcoming of the Greco-Roman philosophical tradition in relation to happiness. Trans/Form/Ação, Marília, v. 37, n. 3, p. 131-142, Set./Dez., 2014.

\begin{abstract}
Following Saint Justin (who, while valuing Greco-Roman Philosophy, claims Christianity to be the "true philosophy"), Augustine grounded his concept of happiness in the philosophical tradition that preceded it, which is conceived by him as a philosophiae portus (port of philosophy). However, as a Christian thinker, Augustine sought to overcome Greco-Roman eudaimonism. The distinction between truth and wisdom, the latter being identified with God, makes Christian faith the arx philosophiae (apex of philosophy), which Augustine calls "our Christian philosophy", the place of "true happiness", which for him is the main purpose of all philosophizing.
\end{abstract}

KEYWORDS: Augustine. Greco-Roman Philosophy. Christian Philosophy. Happiness.

\title{
REFERÊNCIAS
}

AGOSTINHO, Santo. A cidade de Deus: contra os pagãos. Trad. de Oscar Paes Leme. 3. ed. Petrópolis: Vozes; São Paulo: Federação Agostiniana Brasileira, 1991. 2v.

. Confissóes. Trad. de J. Oliveira Santos e A. Ambrósio de Pina. 9. ed. Petrópolis: Vozes, 1988.367 p.

- A vida feliz: diálogo filosófico. Trad. e notas de Nair de Assis Oliveira. São Paulo: Paulinas, 1993.109 p.

. A Trindade. Trad. e notas de Augustino Belmonte. São Paulo: Paulus, 1994. 726 p. (Coleção Patrística, n. 7).

. A verdadeira religião - O cuidado devido aos mortos. Trad. de Nair de Assis Oliveira. São Paulo: Paulus, 2002. 196 p. (Coleção Patrística, n. 19).

. Contra os Acadêmicos - A Ordem - A Grandeza da Alma - O Mestre. Trad. de Agustinho Belmonte. São Paulo: Paulus, 2008.414 p. (Coleçâo Patrística, n. 24).

. A doutrina cristã: manual de exegese e formação cristã. Trad. de Nair de Assis Oliveira. São Paulo: Paulus, 2002. 284 p. (Coleção Patrística, n. 17).

AGUSTÍN, San. Cartas $\left(1^{\circ}\right): 1-123$. In: . Obras completas de san Agustin. Trad., introd. y notas de Lope Cilleruelo. Ed. bilingue. Madrid: La Editorial Católica/BAC, 1986. Tomo 8.

. Cartas $\left(2^{\circ}\right)$ : Ep. 124 - 187. In: Obras completas de san Agustin. Trad., introd. y notas de Lope Cilleruelo. Ed. bilingue. Madrid: La Editorial Católica/BAC, 1987. Tomo 11a.

ARENDT, Hannah. $O$ conceito de amor em santo Agostinho: ensaio de interpretaçáo filosófica. Trad. de Alberto Pereira Dinis. Lisboa: Instituto Piaget, 1997. 
BERALDI, Adriano César Rodrigues. Beatitude e sabedoria em Agostinho: estudo sobre as fontes pagãs no De Beata Vita a partir do uso do termo philosophia. 2010. 106 f. Dissertação (Mestrado em Filosofia) - Universidade Federal do Espírito Santo, Vitória, 2010.

BRACHTENDORF, Johannes. Confissóes de santo Agostinho. Trad. de Milton Camargo Mota. Sáo Paulo: Loyola, 2008. 318 p.

CAMPODONICO, Angelo. Salvezza e verità: saggio su Agostino. Genova : Casa Editrice Merietti, 1989. 215 p.

COPLESTON, Frederick. Historia de la filosofia (II): de san Agustín a Escoto. Trad. de Eugenio Trías. Barcelona: Ariel, 1983.

COURCELLES, Dominique de. Agustín o el genio de Europa. Trad. de Francisca Santa Cruz L. Caracas: Dolmen Ediciones, 1998. 318 p.

GILSON, Étienne. Introduction a l'étude de saint Augustin. 3. ed. Paris: Libraire Philosophique J. Vrin, 1949.

JOLIVET, Régis. San Agustín y el neoplatonismo cristiano. Trad. de G. Blanco et al. Buenos Aires: Ediciones C.E.P.A, 1932. 219 p.

MUÑOZ VEGA, Pablo. Introducion a la sintesis de san Agustín. 2. ed. Quito: Edicione de la Universidade Católica, 1981. 314 p.

RAMOS, Francisco Manfredo Tomás. Bens temporais e vida cristã nas Epistolas de S. Agostinho. Roma: Pontifícia Universitas Gregoriana, 1966.

- A ideia de Estado na doutrina ético-política de S. Agostinho: um estudo do epistolário comparado com o “De civitate Dei”. Sáo Paulo: Loyola, 1984.

SANTOS, Bento Silva. Introdução. In: AGOSTINHO, Santo. Contra os Acadêmicos - A Ordem - A Grandeza da Alma - O Mestre. Trad. de Agustinho Belmonte. São Paulo: Paulus, 2008. (Coleção Patrística, n. 24).

SCIACCA, Michele Federico. San. Agustín. Trad. de Ulpiano Álvarez Díez. Barcelona: Luis Miracle, Editor, 1955. v. 1.

SCIACCA, Michele Federico. Santo Agostino essenziale. Porto Alegre: Instituto de Filosofia/Universidade do Rio Grande do Sul, 1956. 37 p.

Recebido em: 01/09/2014

Aceito em: 03/10/2014 